\title{
Effect of ischaemia on sensory potentials of normal subjects of different ages
}

\author{
GIUSEPPE CARUSO, ORAZIO LABIANCA, AND ERMANNO FERRANNINI \\ From the Clinic of Nervous and Mental Diseases, University of Bari, Bari, Italy
}

SUMMARY In 73 normal subjects, from 10 to 82 years of age, maximum orthodromic sensory nerve conduction velocity was measured in the median nerve before and during a 30 minute period of vascular occlusion. During ischaemia progressive slowing in conduction velocity, decrease in amplitude, and increase in duration of the sensory action potential evoked at wrist and elbow by supramaximal stimulation of digit III were observed. However, a statistically significant difference $(\mathrm{P}<0.05$ to $P<0 \cdot 01$ ) between subjects was noted by grouping them by age: the older the subject, the longer the persistence of sensory response and the less marked the slowing in conduction velocity. The mechanism of the phenomenon has been discussed in relation to a similar longer resistance to ischaemia found in peripheral nerves of diabetic and uraemic patients.

Since the observations of Lewis, Pickering, and Rothschild (1931), much interest has been taken in the sensory and motor phenomena associated with complete arrest of the blood supply to limb. In normal subjects ischaemic paraesthesiae, chiefly consisting of faint tingling, buzzing, or vibrating sensations in the hand or fingers, appear one or two minutes after circulatory occlusion produced from an above-elbow compression, then gradually disappear some minutes later, and are replaced by complete anaesthesia which spreads centripetally up to the point of compression (Kugelberg, 1944; Weddell and Sinclair, 1947; Poole, 1956a; Nathan, 1958).

Age seems to modify the resistance of the nerve to complete circulatory arrest, since Poole (1956a) noted that ischaemic and post-ischaemic paraesthesiae were usually of shorter duration or entirely absent in normal subjects above 61 years of age. Recently, the effect of ischaemia on the excitability of human sensory nerves of normal subjects has been studied by Seneviratne and Peiris (1968a), who recorded at the wrist the sensory potentials evoked by stimuli of supramaximal and submaximal strength applied to digital nerves of the thumb and first three fingers, but they made no attempt to compare the results with the age of the subjects and, as Poole's (1956a) conclusions were mostly based on sub- jective changes in sensation which might be individualized with difficulty, the purpose of the present paper is to determine objectively by electrophysiological techniques whether there are any differences between young and old normal subjects as regards their ability to conduct sensory orthodromic impulses along the median nerve during a 30 minute period of complete occlusion of the blood flow to the arm.

\section{METHODS}

SUBJECTS Seventy-three normal subjects aged from 10 to 82 years were examined by a standard procedure with complete vascular occlusion for 30 minutes, as described below. There were 35 males and 38 females; 25 of them were between 10 and 28, 31 between 30 and 59 , and 17 between 61 and 82 years of age. They were either healthy volunteers or patients without clinical signs or symptoms of neuromuscular diseases. Special attention was paid to the values of blood sugar, blood urea, and haemoglobin levels; care was also taken to ensure that they did not have a history of alcoholism, or that they were not being treated with furantoin. Furthermore, since relaxation was essential to eliminate motor unit activity near the recording electrodes, and because of the duration and the relative discomfort of the experiments, subjects were beforehand told about the kind of disturbances they would undergo 


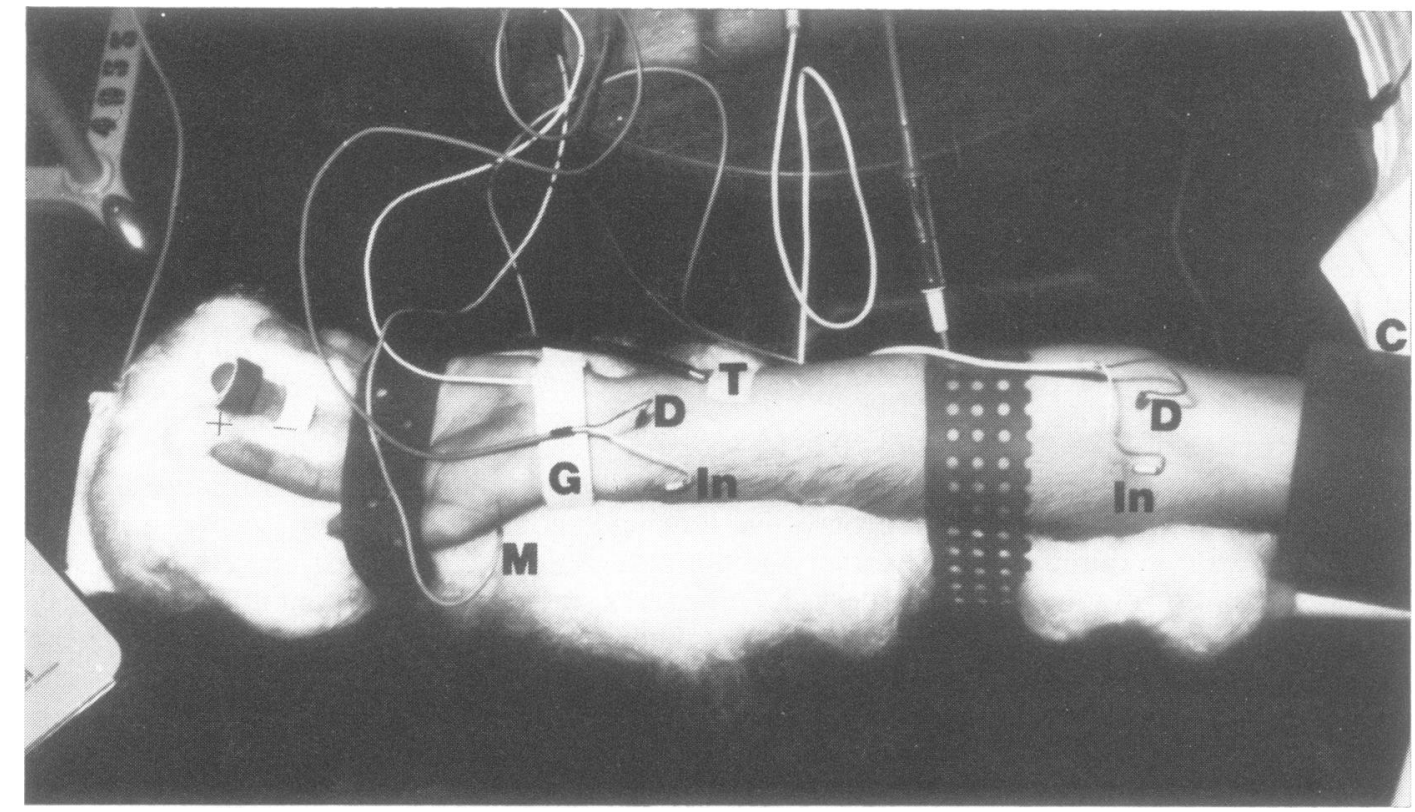

FIG. 1. Position of limb and arrangement of electrodes used for recording orthodromically evoked sensory action potentials. On digit III surface ring electrodes with stimulating cathode situated proximally; $\mathrm{M}-$ concentric needle electrode inserted in abductor pollicis brevis muscle; $\mathrm{G}-$ earth electrode; $\mathrm{D}$ and $\mathrm{In}-$ stigmatic leading-off and remote electrode, respectively; $\mathrm{T}$-thermoneedle connected to electrical thermometer; C-sphygmomanometer cuff.

and selected according to their capacity to collaborate to the utmost.

POSITIONING OF SUBJECT In a warm room $\left(21^{\circ}-\right.$ $23^{\circ} \mathrm{C}$ ), the subject lying comfortably on his back with the abducted upper limb resting on a soft pillow supported by a metal beam (Fig. 1), orthodromic sensory conduction velocity was measured in the median nerve by the technique of Buchthal and Rosenfalck (1966).

STIMULus The stimulus current, a rectangular electrical pulse 150-200 $\mu \mathrm{sec}$ in duration, was supplied by a double-screened transformer (DISAMultistim, type 14GO4) and recorded on a 2-channel electromyograph (DISA 14A20). Surface ring electrodes (DISA 13K69) were placed around digit III, and single shocks of supramaximal intensity (averaging $48 \mathrm{~mA}$, corresponding to eight to nine times the sensory threshold) were delivered at 1 per second frequency. Before stimulating supramaximally, sensory and action potential thresholds at wrist and elbow were determined on each occasion.

RECORDING ELECTRODES The stigmatic electrode, a stainless steel needle Teflon-insulated to $3 \mathrm{~mm}$ from the tip, was inserted in the wrist and elbow as close to the median nerve as possible, judged by the threshold of the muscle action potential. The remote electrode had a bared tip of $5 \mathrm{~mm}$ and was inserted at a transverse distance of about $30 \mathrm{~mm}$ at the level of the stigmatic electrode.

Sensory action potentials were recorded from wrist and elbow via an input-transformer (DISA 14B15), and were simultaneously displayed on the two channels of the electromyograph.

In all subjects 10 to 15 single sweeps and one photographic superposition of 20 responses evoked by supramaximal stimulation on digit III were recorded on $35 \mathrm{~mm}$ photographic paper with a Cossor camera (DISA 51C40) before vascular occlusion and every five minutes exactly during ischaemia. Shorter intervals of time between each series of stimulations were used after 10 to 20 minutes from the onset of ischaemia in order to determine the exact moment of disappearance of the sensory action potential at the elbow.

MEASUREMENT For analysis of records, the selected films were placed under a magnifying glass and 
measurements were made with greatest accuracy in four to five consecutive examples of each stimulation series.

The conduction time was measured from the onset of the stimulus artefact to the first positive peak of the unipolarly recorded action potential. The potential amplitude was measured peak-to-peak, and the duration from the onset of the first positive phase to the intersection of the negative-positive deflection with the base line.

The distances from the stimulating cathode on digit III to the stigmatic leading-off electrode on the wrist and from this to the stigmatic electrode on the elbow were measured by two observers as accurately as possible, taking only the values which did not differ by more than $2 \mathrm{~mm}$.

PRODUCTION OF ISCHAEMIA Vascular occlusion was achieved by rapidly inflating a $13 \mathrm{~cm}$ wide cuff of a sphygmomanometer previously situated round the arm at about 7 to $8 \mathrm{~cm}$ above the elbow to a pressure of 250 to $300 \mathrm{mmHg}$, but in all cases not less than 80 to $100 \mathrm{mmHg}$ above the resting value of systolic blood pressure.

The arrest of blood flow always lasted exactly 30 minutes, and during this period sensory action potentials were recorded in all subjects at five minute intervals. Shorter intervals of time were also used between the 10th and 20th minute of ischaemia. The exact times were registered on a stop-watch.

Owing to the duration of the experiment and to local compression of muscles, however, pressures of the above-mentioned values gave rise to some discomfort, particularly during the last minutes of the occlusion.

CONTROL OF TEMPERATURE The near-nerve temperature was measured by a thermo-needle previously inserted close to the median nerve on the volar side of the forearm and connected to an electrical thermometer (ELLAB TE-3). Cooling was minimized by covering the hand and the forearm with a thick layer of cottonwool, and with an infrared heater near by. In this way, the near-nerve temperature, controlled before circulatory arrest and at five minute intervals during occlusion, did not vary by more than $1^{\circ} \mathrm{C}$, on the average $\left(34 \cdot 6 \pm 0 \cdot 2^{\circ} \mathrm{C}\right.$ before occlusion, and $33.8 \pm 0.3^{\circ} \mathrm{C}$ at the end of the 30 minute period ischaemia). Thus, variations in temperature are not likely to have affected the results.

STATISTICAL TREATMENT The data were analysed statistically by using a completely randomized design. The significance of the results was then assessed by comparing the observed value with the theoretical F-value reported in an ' $F$ ' table.

TABLE 1

MEAN VALUES OF DISTAL CONDUCTION TIME, DISTANCES, MAXIMUM CONDUCTION VELOCITY, POTENTIAL AMPLITUDE, AND DURATION AT WRIST AND ELBOW BEFORE VASCULAR OCCLUSION

\begin{tabular}{|c|c|c|c|c|c|c|}
\hline & \multicolumn{6}{|c|}{ Age groups $(y r)$} \\
\hline & \multicolumn{2}{|c|}{${ }_{10-28}^{1}$} & \multicolumn{2}{|c|}{$\stackrel{2}{30-59}$} & \multicolumn{2}{|c|}{$\stackrel{3}{61-82}$} \\
\hline & Mean value & $S D$ & Mean value & $S D$ & Mean value & $S D$ \\
\hline Conduction time digit III-wrist (msec) & $\begin{array}{l}2 \cdot 8 \pm 0 \cdot 10 \\
(\mathrm{Bb})\end{array}$ & $0 \cdot 51$ & $\begin{array}{l}3 \cdot 2 \pm 0 \cdot 09 \\
(\mathrm{Aa})\end{array}$ & $0 \cdot 51$ & $\begin{array}{l}3 \cdot 5 \pm 0 \cdot 13 \\
\quad(\mathrm{Aa})\end{array}$ & $0 \cdot 55$ \\
\hline Distance digit III-wrist (cm) & $\begin{array}{c}15 \cdot 5 \pm 0 \cdot 26 \\
(\mathrm{Aa})\end{array}$ & $1 \cdot 31$ & $\begin{array}{c}16 \cdot 3 \pm 0 \cdot 28 \\
(\mathrm{Aa})\end{array}$ & $1 \cdot 55$ & $\begin{array}{c}16 \cdot 2 \pm 0.36 \\
(\mathrm{Aa})\end{array}$ & $1 \cdot 48$ \\
\hline Distance wrist-elbow (cm) & $\begin{array}{l}21 \cdot 6 \pm 0 \cdot 43 \\
\quad(\mathrm{Aa})\end{array}$ & $2 \cdot 15$ & $\begin{array}{l}22 \cdot 2 \pm 0 \cdot 34 \\
\quad(\mathrm{Aa})\end{array}$ & $1 \cdot 90$ & $\begin{array}{l}21 \cdot 7 \pm 0.48 \\
(\mathrm{Aa})\end{array}$ & 1.98 \\
\hline Conduction velocity digit III-wrist (m/sec) & $\begin{array}{l}53 \cdot 8 \pm 1 \cdot 45 \\
\quad(\mathrm{Aa})\end{array}$ & $7 \cdot 26$ & $\begin{array}{l}51 \cdot 1 \pm 1 \cdot 17 \\
(\mathrm{AaB})\end{array}$ & $6 \cdot 41$ & $\begin{array}{l}47 \cdot 1 \pm 1 \cdot 49 \\
(\mathrm{Bb})\end{array}$ & $6 \cdot 16$ \\
\hline Conduction velocity wrist-elbow $(\mathrm{m} / \mathrm{sec})$ & $\begin{array}{l}63 \cdot 9 \pm 0 \cdot 70 \\
(\mathrm{Bb})\end{array}$ & $3 \cdot 49$ & $\begin{array}{l}61 \cdot 0 \pm 0 \cdot 71 \\
(\mathrm{Aa})\end{array}$ & $3 \cdot 92$ & $\begin{array}{l}58 \cdot 3 \pm 1 \cdot 29 \\
(\text { Aa) }\end{array}$ & $5 \cdot 33$ \\
\hline Potential amplitude at wrist $(\mu \mathrm{V})$ & $\begin{array}{c}29 \cdot 1 \pm 2 \cdot 32 \\
(\mathrm{Ab})\end{array}$ & $11 \cdot 58$ & $\begin{array}{c}22 \cdot 2 \pm 1 \cdot 84 \\
(\mathrm{AaB})\end{array}$ & $10 \cdot 24$ & $\begin{array}{c}18 \cdot 3 \pm 2 \cdot 08 \\
(\mathrm{aB})\end{array}$ & $8 \cdot 57$ \\
\hline Potential amplitude at elbow $(\mu \mathrm{V})$ & $\begin{array}{l}13 \cdot 8 \pm 1 \cdot 30 \\
\text { (Aa) }\end{array}$ & $6 \cdot 52$ & $\begin{array}{l}10 \cdot 9 \pm 0.85 \\
(\mathrm{AaBb})\end{array}$ & $4 \cdot 71$ & $\begin{array}{l}8 \cdot 9 \pm 0 \cdot 79 \\
(\mathrm{Bb})\end{array}$ & $3 \cdot 27$ \\
\hline Potential duration at wrist (msec) & $\begin{array}{c}1.4 \pm 0.04 \\
\text { (Aa) }\end{array}$ & $0 \cdot 19$ & $\begin{array}{c}1.6 \pm 0.05 \\
(\mathrm{Cc})\end{array}$ & $0 \cdot 27$ & $\begin{array}{c}1 \cdot 9 \pm 0.05 \\
(\mathrm{Bb})\end{array}$ & $0 \cdot 23$ \\
\hline Potential duration at elbow (msec) & $\begin{array}{c}2 \cdot 2 \pm 0.07 \\
(\mathrm{Bb})\end{array}$ & $0 \cdot 35$ & $\begin{array}{l}2 \cdot 7 \pm 0.08 \\
\text { (Aa) }\end{array}$ & 0.44 & $\begin{array}{l}2 \cdot 8 \pm 0 \cdot 13 \\
(\mathrm{Aa})\end{array}$ & 0.53 \\
\hline
\end{tabular}

Values marked by the same letter do not show statistical difference. Capital letters refer to $\mathrm{P}<0.01 ;$ small letters refer to $\mathrm{P}<0.05$. 


\section{RESULTS}

BEFORE VASCULAR OCCLUSION Each age group is reported separately. Table 1 gives the mean values of distal conduction time, maximum orthodromic sensory conduction velocity from digit III to wrist and from wrist to elbow, and the amplitude and duration of the sensory action potentials evoked at wrist and elbow by supramaximal stimulation of digit III. Expressed in centimetres, mean values of the conduction distances measured superficially along the nerve are also reported in Table 1.

Table 1 demonstrates that the maximum conduction velocity decreases with increase in age of the subjects, and that the differences between age groups are statistically significant both in the distal and proximal segment (Fig. 2).

Because of a greater temporal dispersion over the longer distance in the conduction of volleys along sensory fibres (Buchthal and Rosenfalck, 1966; Behse and Buchthal, 1971), the amplitude of the action potentials evoked by supramaximal stimuli to digit III is smaller at the elbow than at the wrist $(P<0.01)$ in all three groups. However, mean values of potential amplitude of 10 to 28 and 61 to 82 year old subjects differ by $10.8 \mu \mathrm{V}$ $(\mathrm{P}<0.01)$ and $4.9 \mu \mathrm{V}(\mathrm{P}<0.01)$ respectively at wrist and elbow.
The duration of sensory action potential recorded unipolarly depends on the conduction distance between stimulating and recording electrodes (Buchthal and Rosenfalck, 1966) and on the velocity of impulses along nerve fibres. The response to supramaximal stimuli applied to digit III is, thus, shorter at the wrist than at the elbow $(P<0.01)$. From Table 1 it can, however, be seen that the average sensory potential duration is greater in subjects from 61 to 82 years of age than in the younger groups, both distally at the wrist and proximally at the elbow.

DURING VASCULAR OCCLUSION (a) Clinical data In the majority of the younger subjects rapid inflation of the pneumatic cuff round the upper arm to $80-120 \mathrm{mmHg}$ above arterial pressure was followed within one or two minutes by ischaemic paraesthesiae consisting of faint tingling or vibrating sensations in the hand and fingers which, however, disappeared a few minutes later. Ten to 15 minutes after the cuff had been rapidly inflated well over the systolic pressure, there was no longer appreciation of touch, position, and pressure, and subjects $\stackrel{\otimes}{\circ}$ reported considerable excitability changes mostly consisting of an increase of sensory threshold. After about 20 minutes of ischaemia the subjects were unable to feel the stimulus applied to theo

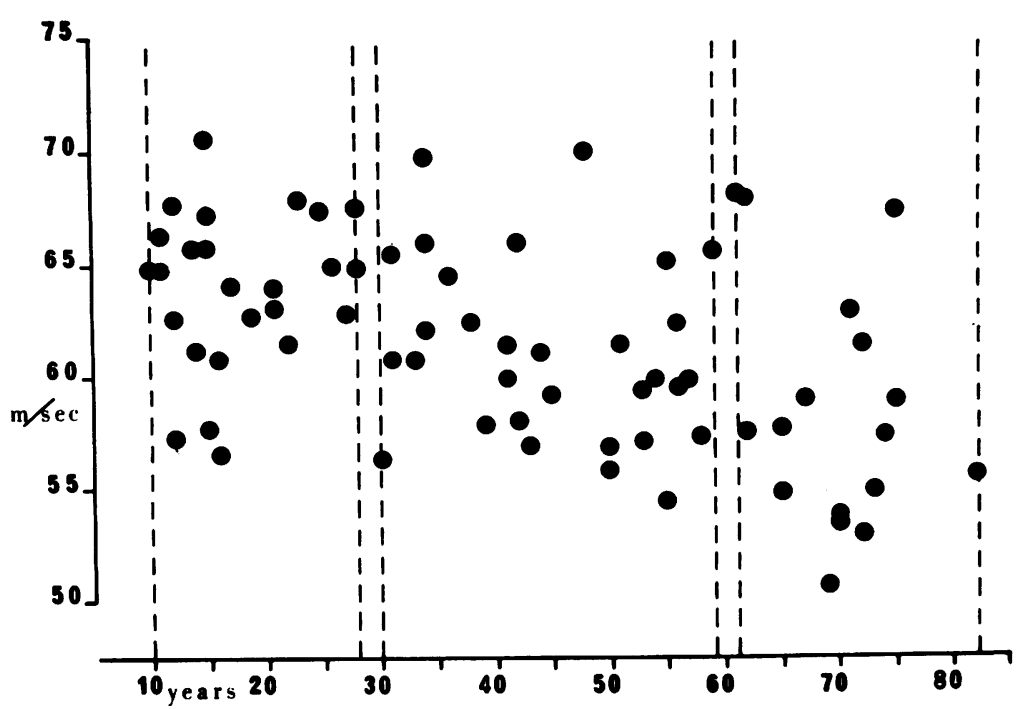

FIG. 2. Values of maximum orthodromic sensory conduction velocity in median nerve from wrist to elbow plotted against age $(73$ subjects from 10 to 82 years). Groups are delimited by broken line. As age increases, so conduction velocity decreases, the differences between each group being statistically significant $(P<0.01)$. 

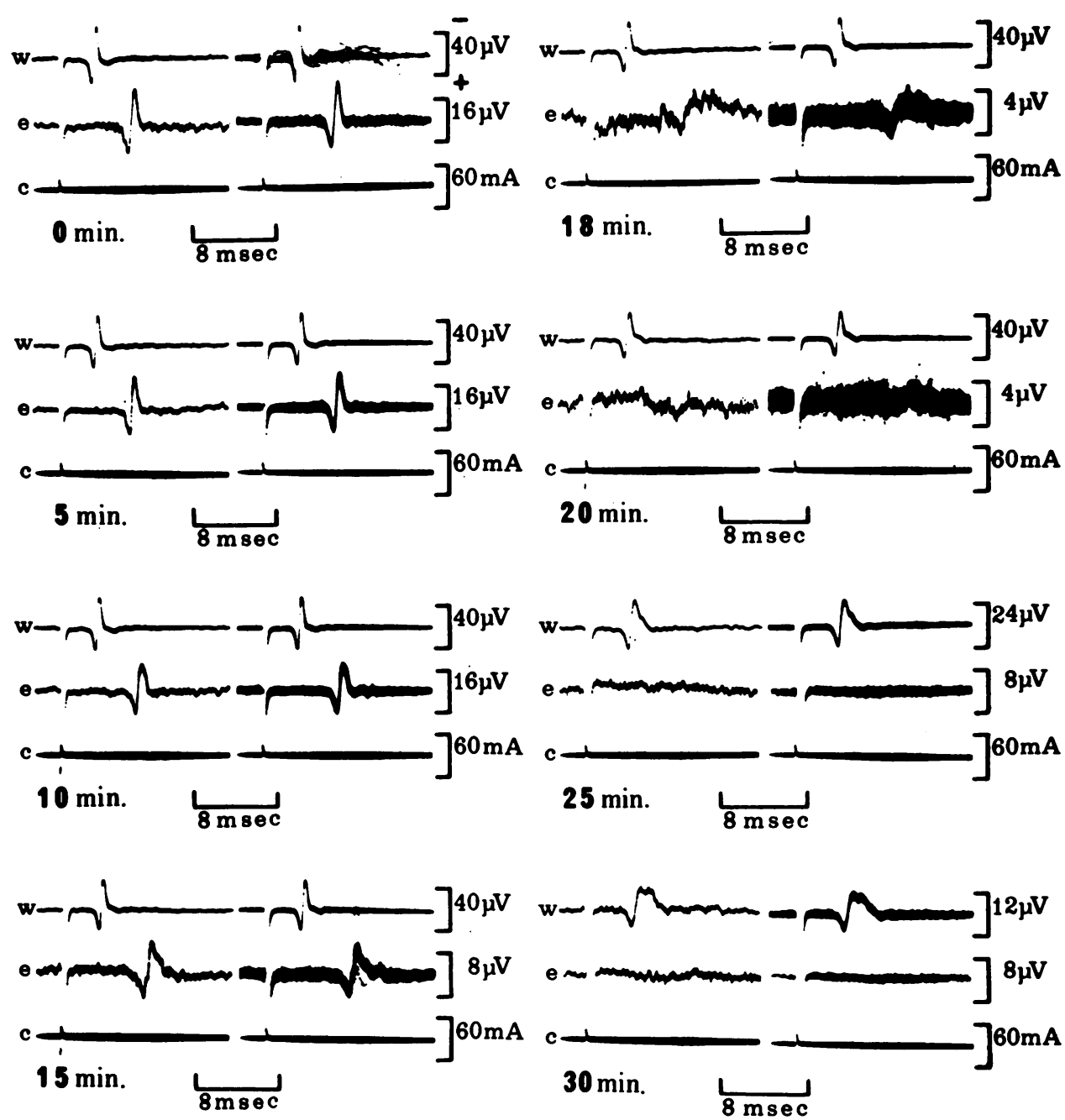

FIG. 3. Sensory nerve action potentials evoked by supramaximal stimulation of digit III and recorded unipolarly from wrist (w) and elbow (e) before and during a 30 minute period of complete vascular occlusion of limb. Stimulus current (nine times the sensory threshold measured before occluding blood flow to arm) indicated by c. On the right of each single sweep 20 photographically superimposed traces. The effects of circulatory occlusion are apparent and higher at a greater conduction distance from stimulating cathode-that is, at the elbow. Subject M.C., female, 28 years old.

finger and complained of discomfort and painful paraesthesiae at the point of compression of the muscle, while at the onset of the experiment such an occlusion was readily tolerated. At the same time, many of them could no longer feel the limb below the vascular occlusion.

In sharp contrast to the symptoms described above in the younger subjects are the disorders occurring after circulatory arrest in subjects from 61 to 82 years of age. When present, ischaemic paraesthesiae often consisted only of a faint buzzing usually confined to the fingers, setting in six to nine minutes after occlusion. Increase of the sensory threshold was generally absent or very small, and the electrical stimulus could still be felt, even without having any response detect- 
able with high amplification and photographic superposition of 20 traces, until the 30 minutes of ischaemia had elapsed. Pain was also often reported absent at the level of compression of muscle.

(b) Electrophysiological data The sudden and complete occlusion of the blood flow to the arm led to progressive arrest of the orthodromic conduction of impulses along sensory fibres of the median nerve. While the responses were generally little affected during the first five minutes of ischaemia, slowing of maximum conduction velocity was seen; then the amplitude of the evoked sensory potential began to decrease and its duration to increase (Fig. 3). However, probably because the nerve fibres contributing to the action potential are not uniformly affected by ischaemia (thus accentuating the temporal dispersion of the impulses), the greater the distance between the stimulating cathode and the leading-off electrode, the more evident and earlier was the appearance of the above phenomena. In fact, while in only very few circumstances could no orthodromic action potentials be recorded at the wrist after the 30 minute period of ischaemia, very seldom was there a case when the responses were seen at the elbow after 15 to 20 minutes (Fig. 4). For this reason, the calculations from the values taken at the elbow are limited to the first 15 minutes of ischaemia.

1. MAXIMUM ORTHODROMIC SENSORY CONDUCTION VELOCITY Each age group being considered separately, Figs 5 and 6, for segment from digit III to wrist and wrist to elbow respectively, show progressive slowing in maximum sensory con-

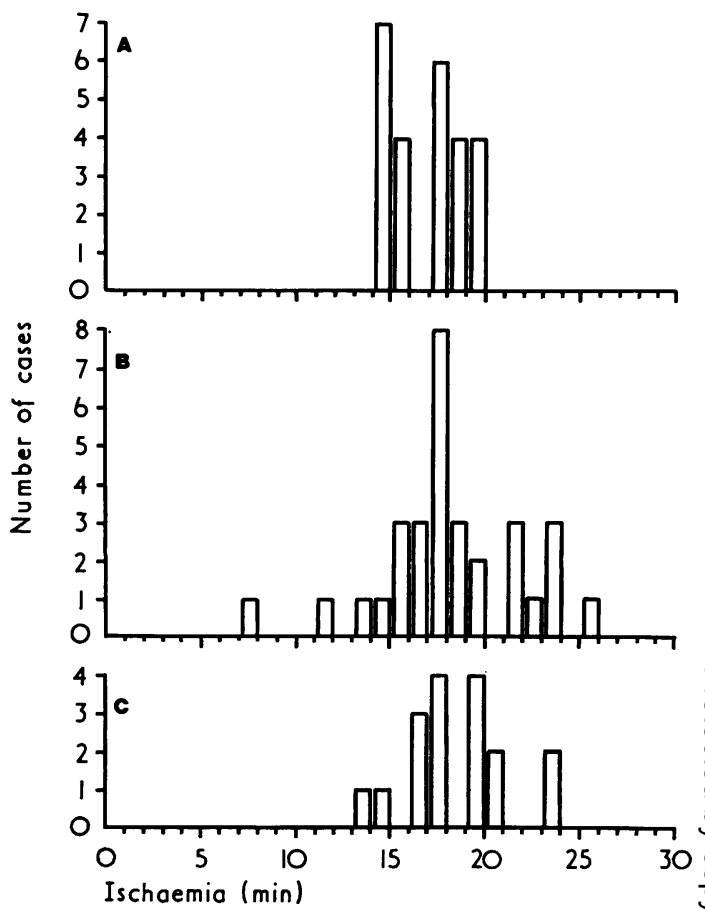

FIG. 4. Case distribution of the persistence of the $\overrightarrow{0}$ sensory response at the elbow during a 30 minute $\mathrm{\omega}$ period of vascular occlusion. In A subjects from 10 to 28 years of age, in B subjects from 30 to 59 , and in $\mathrm{C}$ subjects from 61 to 82 years. On the ordinate the number of cases; on the abscissa the duration of ischaemia expressed in minutes. Longer persistence of the sensory response in older subjects is evident.

TABLE 2

MAXIMUM SENSORY CONDUCTION VELOCITY FROM DIGIT III TO WRIST AND FROM WRIST TO ELBOW DURING VASCULAR OCCLUSION: PROGRESSIVE DECREASE AS PER CENT OF PRE-ISCHAEMIC VALUE

\begin{tabular}{|c|c|c|c|c|c|c|c|c|c|c|c|c|}
\hline \multirow{2}{*}{$\begin{array}{c}\begin{array}{c}\text { Ischaemia } \\
\text { (min) }\end{array} \\
5 \\
10\end{array}$} & \multicolumn{6}{|c|}{ Digit III-wrist } & \multicolumn{6}{|c|}{ Wrist-elbow } \\
\hline & \multicolumn{2}{|c|}{$\stackrel{1}{10-28}$} & \multicolumn{2}{|c|}{$\stackrel{2}{30-59}$} & \multicolumn{2}{|c|}{$\stackrel{3}{61-82}$} & \multicolumn{2}{|c|}{$\underset{10-28}{1}$} & \multicolumn{2}{|c|}{$\stackrel{2}{30-59}$} & \multicolumn{2}{|c|}{$\stackrel{3}{61-82}$} \\
\hline $\begin{array}{r}5 \\
10 \\
15 \\
20 \\
25 \\
30\end{array}$ & $\begin{array}{l}(25) \\
(25) \\
(25) \\
(24) \\
(24) \\
(23)\end{array}$ & \begin{tabular}{r|}
$1 \cdot 4$ \\
$5 \cdot 1$ \\
$10 \cdot 4$ \\
$17 \cdot 1$ \\
$26 \cdot 5$ \\
$36 \cdot 3$
\end{tabular} & $\begin{array}{l}(31) \\
(31) \\
(31) \\
(30) \\
(31) \\
(26)\end{array}$ & $\begin{array}{r}3 \cdot 2 \\
5 \cdot 9 \\
9 \cdot 5 \\
15 \cdot 5 \\
22 \cdot 2 \\
27 \cdot 1\end{array}$ & $\begin{array}{l}(17) \\
(17) \\
(16) \\
(17) \\
(16) \\
(16)\end{array}$ & $\begin{array}{r}2 \cdot 8 \\
6 \cdot 2 \\
9 \cdot 3 \\
13 \cdot 4 \\
19 \cdot 7 \\
27 \cdot 6\end{array}$ & $\begin{array}{l}(25) \\
(25) \\
(25)\end{array}$ & $\begin{array}{r}5.6 \\
16.4 \\
30.9\end{array}$ & $\begin{array}{l}(31) \\
(31) \\
(29)\end{array}$ & $\begin{array}{r}4.0 \\
11.5 \\
22.0\end{array}$ & $\begin{array}{l}(17) \\
(17) \\
(16)\end{array}$ & $\begin{array}{r}2.9 \\
9.4 \\
18.5\end{array}$ \\
\hline
\end{tabular}

Figures in parentheses refer to number of subjects calculated at that moment of ischaemia.

Age groups as in Table 1. 
TABLE 3

AMPLITUDE OF SENSORY NERVE ACTION POTENTIAL AT WRIST AND ELBOW EVOKED BY SUPRAMAXIMAL STIMULATION OF DIGIT III DURING VASCULAR OCCLUSION: PROGRESSIVE DECREASE AS PER CENT OF PRE-ISCHAEMIC VALUE

\begin{tabular}{|c|c|c|c|c|c|c|c|c|c|c|c|c|}
\hline \multirow{2}{*}{$\begin{array}{c}\begin{array}{c}\text { Ischaemia } \\
\text { (min) }\end{array} \\
5 \\
10\end{array}$} & \multicolumn{6}{|c|}{ Wrist } & \multicolumn{6}{|c|}{ Elbow } \\
\hline & \multicolumn{2}{|c|}{$\begin{array}{c}1 \\
10-28\end{array}$} & \multicolumn{2}{|c|}{$\stackrel{2}{30-59}$} & \multicolumn{2}{|c|}{$\begin{array}{c}3 \\
61-82\end{array}$} & \multicolumn{2}{|c|}{$\stackrel{1}{10-28}$} & \multicolumn{2}{|c|}{$\stackrel{2}{30-59}$} & \multicolumn{2}{|c|}{$\stackrel{3}{61-82}$} \\
\hline $\begin{array}{r}5 \\
10 \\
15 \\
20 \\
25 \\
30\end{array}$ & $\begin{array}{l}(25) \\
(25) \\
(25) \\
(24) \\
(24) \\
(23)\end{array}$ & $\begin{array}{r}6 \cdot 6 \\
7 \cdot 9 \\
14 \cdot 5 \\
32 \cdot 1 \\
60 \cdot 4 \\
82 \cdot 7\end{array}$ & $\begin{array}{l}(31) \\
(31) \\
(31) \\
(30) \\
(31) \\
(26)\end{array}$ & $\begin{array}{r}7 \cdot 3 \\
9 \cdot 6 \\
14 \cdot 6 \\
27 \cdot 9 \\
50 \cdot 4 \\
66 \cdot 1\end{array}$ & $\begin{array}{l}(17) \\
(17) \\
(16) \\
(17) \\
(16) \\
(16)\end{array}$ & $\begin{array}{r}7 \cdot 3 \\
10 \cdot 9 \\
15 \cdot 4 \\
27 \cdot 1 \\
43 \cdot 8 \\
62 \cdot 3\end{array}$ & $\begin{array}{l}(25) \\
(25) \\
(25)\end{array}$ & $\begin{array}{r}7 \cdot 2 \\
16 \cdot 6 \\
60 \cdot 3\end{array}$ & $\begin{array}{l}\text { (31) } \\
(31) \\
(29)\end{array}$ & $\begin{array}{l}11 \cdot 5 \\
22 \cdot 7 \\
51 \cdot 1\end{array}$ & $\begin{array}{l}(17) \\
(17) \\
(16)\end{array}$ & $\begin{array}{l}11 \cdot 4 \\
19 \cdot 8 \\
41 \cdot 9\end{array}$ \\
\hline
\end{tabular}

Figures in parentheses refer to number of subjects calculated at that moment of ischaemia. Age groups as in Table 1.

duction velocity in $\mathrm{m} / \mathrm{sec}$ as a function of the duration of circulatory occlusion. In Table 2 the decrease in conduction velocity, both in the distal and proximal nerve segment, is expressed in per cent of the corresponding pre-ischaemic value.

As far as the conduction velocity from digit III to the wrist is concerned, Fig. 5 and Table 2 indicate more or less the same slowing in all

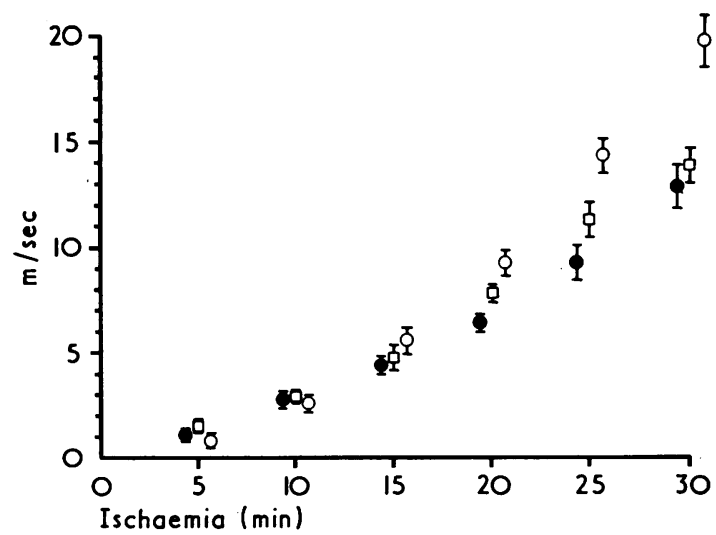

FIG. 5. Mean slowing of maximum sensory nerve conduction velocity from digit III to wrist plotted as function of occlusion duration. Ordinate: decrease in conduction velocity; abscissa: minutes of ischaemia. Open circles: subjects 10 to 28 years old; squares: subjects 30 to 59; closed circles: subjects 61 to 82 years. Up to 10 minutes' complete occlusion of blood flow, the slowing in velocity is almost of the same value in each age group; after 15 minutes, however, it becomes progressively more marked in younger subjects.

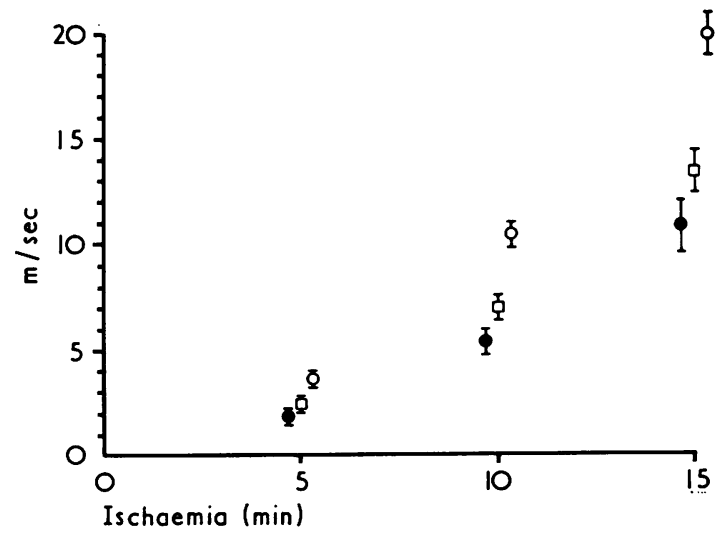

FIG. 6. Plot of slowing of maximum sensory nerve conduction velocity across the segment from wrist to elbow during 15 minutes of ischaemia. Ordinate: decrease in conduction velocity expressed in $\mathrm{m} / \mathrm{sec}$; abscissa: vascular occlusion duration expressed in minutes. Subject groups as in Fig. 5. The difference in reduction of velocity between the younger and older subjects appears already significant $(P<0.01)$ after $a$ 15 minute period of circulatory occlusion; no statistically significant difference could be noted between the third and the second group.

three groups during the first 10 minutes of ischaemia. This probably depends on the short conduction distance between the stimulating cathode and the distal leading-off electrode. After 15 minutes of ischaemia, however, Fig. 5 illustrates a decrease in conduction velocity in the younger subjects which already differs significantly $(\mathrm{P}<0.05)$ from that of the older ones. After 30 minutes the differences also appear 
highly significant $(P<0.01)$ when comparing the slowing found in the first group with that obtained in the second, while the differences between the group 30 to 59 years of age and the third group have no statistical value.

The differences between the younger and the older subjects already appear marked after five minutes and highly significant $(P<0.01)$ after 15-probably owing to a greater conduction distance between the stimulating cathode on digit III and the recording electrode at the elbow -across the more proximal nerve segment from wrist to elbow (Fig. 6 and Table 2). Yet, even after 15 minutes, comparison between the second and the third group fails to show any significant difference.

2. SENSORY ACTION POTENTIAL AMPLITUDE As ischaemia continues, the amplitude of the evoked sensory action potential decreases to almost complete disappearance owing to dispersion and desynchronized conduction of the volley along nerve fibres. Because of the more marked temporal dispersion, the phenomenon is clearer with increase of the distance from the stimulating electrode-that is, it is seen much more early at the elbow than at the wrist. However, where the potential disappearance at the elbow is plotted separately for each group against ischaemia duration (Fig. 4), it is clear that it also depends on the age of the subjects; in fact, in the older ones there is a clear tendency for the response to persist longer. Furthermore, Figs 7 and 8 show, as a function of the duration of ischaemia, the decrease (in $\mu \mathrm{V}$ ) of the amplitude of the sensory action potential evoked at the wrist and elbow respectively by supramaximal stimulation of digit III. In Table 3 the progressive decrease of amplitude is also indicated as per cent deviation of the mean value recorded before circulatory arrest.

At the wrist (Fig. 7 and Table 3), up to 20 minutes after vascular occlusion, no difference between the mean values of the three groups can be seen; after 25 to 30 minutes, however, the differences take on statistical significance both between the subjects from 10 to 28 and 30 to 59 years $(P<0.05$ to $P<0.01)$, and between those from 10 to 28 and from 61 to 82 years of age $(P<0.01)$. As at the wrist, the mean values of the decrease in sensory potential amplitude at the

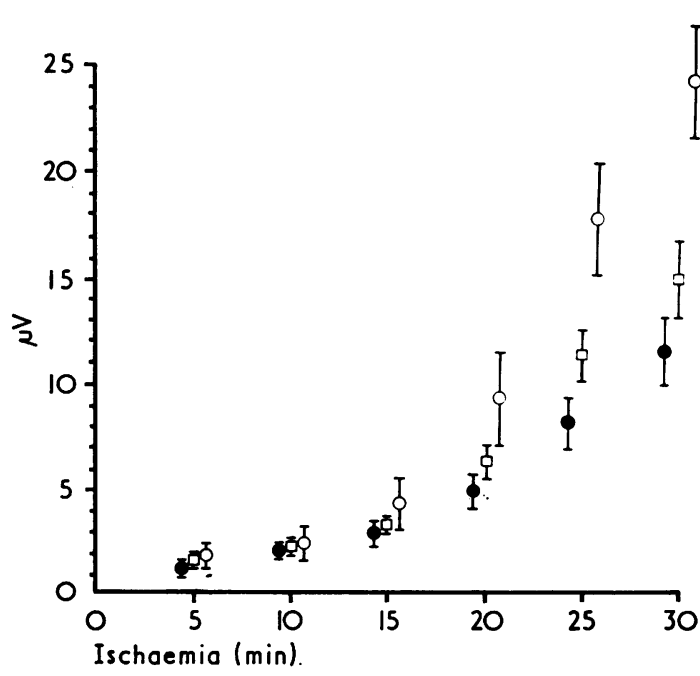

FIG. 7. The decrease in amplitude of supramaximally evoked sensory action potential recorded at the wrist (ordinate) plotted against minutes of occlusion (abscissa). Subject groups as in Fig. 5. Up to 20 minutes from occlusion no difference can be seep between each group of subjects; after this, however $\frac{\vec{P}}{\text { i }}$ the first group values are significantly different fron those obtained in both the second and third group $(P<0.05$ to $P<0.01)$.

elbow (Fig. 8 and Table 3) show no differences between various groups at the beginning, while after 15 minutes of ischaemia the findings obtained in the first and third, and in the second and third group have statistically significant differences $(P<0.05)$.

3. SENSORY ACTION POTENTIAL DURATION In SO far as the duration of the sensory action potential with respect to the course of the circulatory arrest is concerned, Table 4 and Figs 9 and 10, which refer to the sensory action potentials evoked on the wrist and elbow respectively, show its progressive increase as ischaemia proceeds. Thirty minutes from the arrest of the blood flow mean values of the sensory potential duration at the wrist exceed the pre-ischaemic values by $1 \cdot 7 \pm 0 \cdot 19 \mathrm{msec}$ in subjects from 10 to 28 , by $1 \cdot 6 \pm 0 \cdot 16 \mathrm{msec}$ in subjects from 30 to 59 , and by $1 \cdot 8 \pm 0 \cdot 19 \mathrm{msec}$ in those from 61 to 82 years of age (Fig. 9). At the elbow, after 15 minutes of ischaemia, the increase in potential duration averages $1 \cdot 1 \pm 0 \cdot 11 \mathrm{msec}, 1 \cdot 4 \pm 0 \cdot 18$ $\mathrm{msec}$ and $1 \cdot 5 \pm 0.20 \mathrm{msec}$, for each group respec- 
TABLE 4

DURATION OF SENSORY NERVE ACTION POTENTIAL AT WRIST AND ELBOW EVOKED BY SUPRAMAXIMAL STIMULATION OF DIGIT III DURING VASCULAR OCCLUSION: PROGRESSIVE INCREASE AS PER CENT OF PRE-ISCHAEMIC VALUE

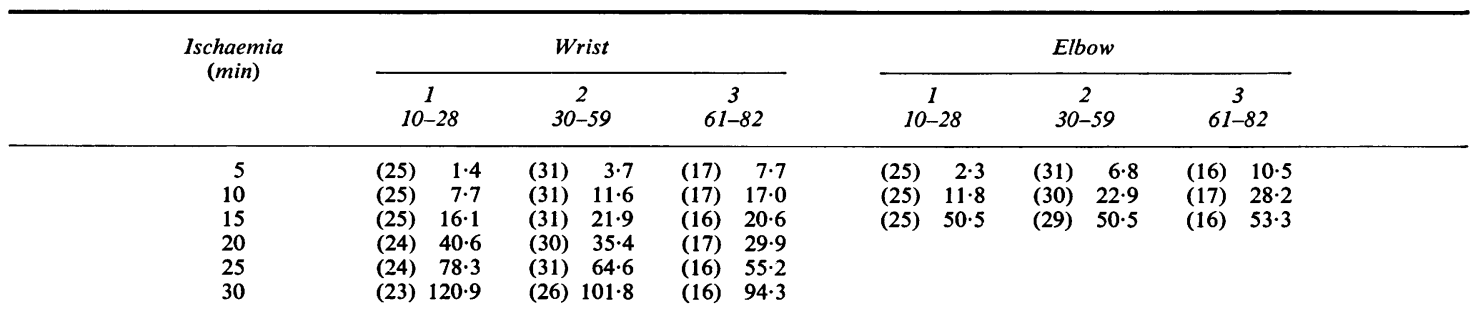

Figures in parentheses refer to number of subjects calculated at that moment of ischaemia.

Age groups as in Table 1.

tively (Fig. 10). Thus, it is clear that both at the wrist and elbow during ischaemia sensory potential duration behaves differently from potential amplitude and conduction velocity: in fact, its mean increase is more evident in older than in younger subjects. On the other hand, the differences between mean values calculated from the three groups assume significance $(\mathrm{P}<0.05$ to $P<0.01)$ only at the onset of ischaemia.

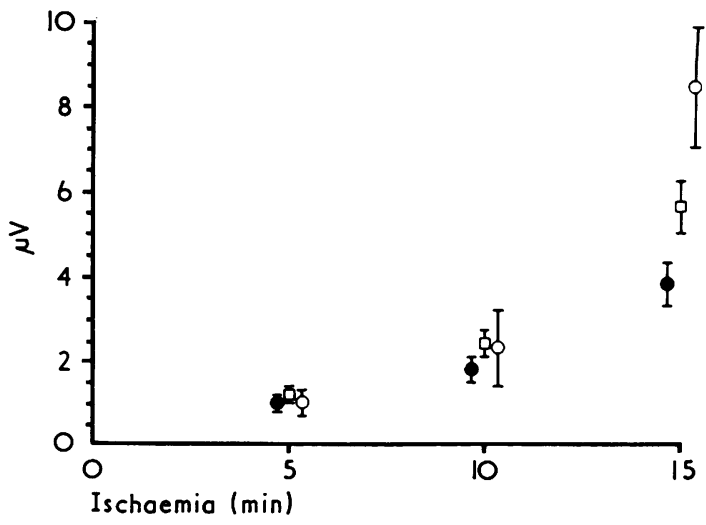

FIG. 8. Diagram of the progressive decrease in amplitude of the sensory nerve action potential recorded at the elbow after supramaximal stimulation of digit III. On the ordinate the decrease in potential amplitude is expressed in $\mu V$; on the abscissa the duration of occlusion of blood flow in minutes. Subject groups as in Fig. 5. After 5 and 10 minutes of ischaemia no significant difference could be seen between each group; after 15 minutes the mean decrease in amplitude observed in the first and in the second group differs significantly $(P<0.05)$ from that noted in the third.

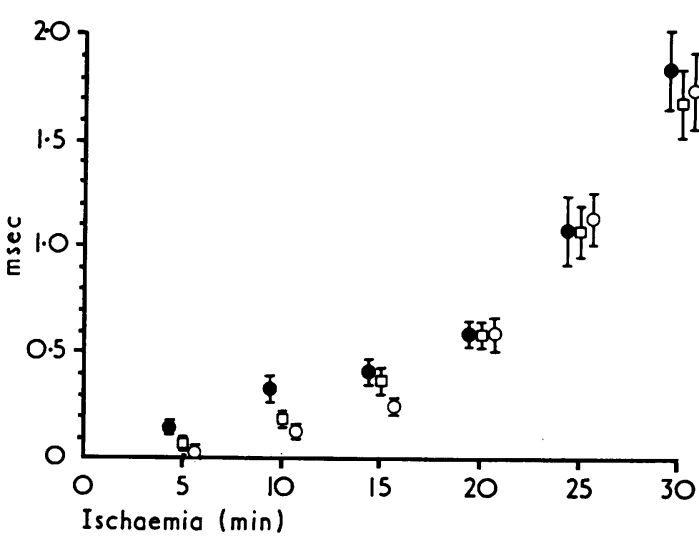

FIG. 9. Relationship of the increase in duration of the sensory nerve action potential recorded at the wrist expressed in msec (ordinate) to the duration of occlusion of blood supply expressed in minutes (abscissa). Subject groups as in Fig. 5. The potential duration increases as ischaemia continues. Differences between age groups with respect to potential amplitude and maximum conduction velocity are only significant $(P<0.05$ to $P<0.01)$ at the beginning of the experiment.

\section{DISCUSSION}

In 73 normal subjects of different ages, the mean values of maximum sensory nerve conduction velocity measured along the median nerve before occluding the blood flow to the arm correspond to the figures obtained by Buchthal and Rosenfalck (1966) in normal subjects of corresponding ages. In close agreement with these and other workers (Norris, Shock, and Wagman, 1953; 


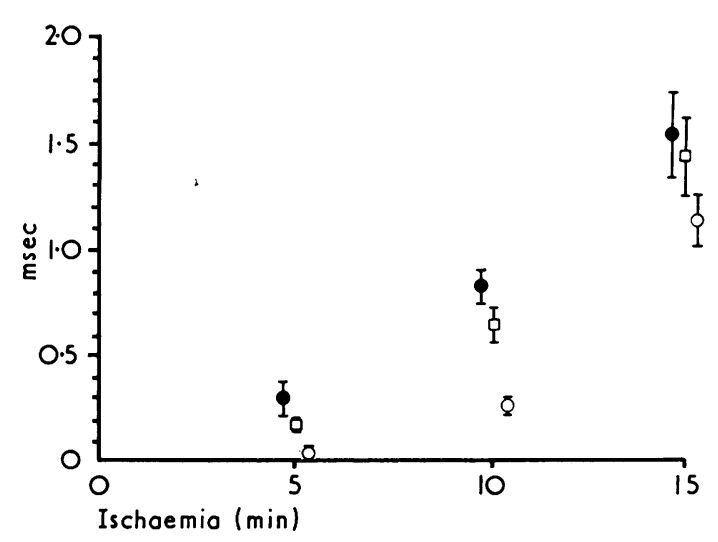

FIG. 10. Plot of the increase in duration of the supramaximally evoked sensory nerve action potential recorded at the elbow during ischaemia. On the ordinate the increase in duration is expressed in msec; on the abscissa blood-flow occlusion is indicated in minutes. Subject groups as in Fig. 5. By continuing the occlusion, potential duration increases. Here also, as at the wrist, however, the differences between mean values obtained in each group are statistically significant $(P<0.05$ to $P<0.01)$ only at the beginning.

Behse and Buchthal, 1971), we also found that conduction velocity decreases as age increases, the differences between the subjects from 10 to 28,30 to 59 , and 61 to 82 years of age being highly significant statistically $(\mathrm{P}<0.01)$. Age also modifies the amplitude and duration of the evoked sensory action potential, and we observed that amplitude decreases and duration increases almost in parallel. So far as comparison between the distal and proximal nerve segments is concerned, we found, moreover, that the differences between young and old subjects are more marked when comparing the values of the proximal segment, probably on account of the larger distance and consequently the higher temporal dispersion in conducting the volleys along nerve fibres.

In our subjects, no particularly significant differences either in the length of the examined nerve segments (Table 1), or in the values of the near-nerve temperature were found; the slowing in velocity with advancing years therefore requires other explanations.

In normal subjects over the age of 60 years, a significant fall in fibre density with a propor- tional decrease of large fibres was observed in the anterior tibial (Swallow, 1966) and in sural and radial nerves (O'Sullivan and Swallow, 1968). However, the loss of some large fibres cannot explain the slowing in conduction observed in the older subjects, since there is still $80 \%$ or more of the fastest fibres present (Buchthal, 1972).

In isolated fibres of the sural nerve of normal subjects above 65 years of age, Lascelles and Thomas (1966) demonstrated the presence of irregularities of internodal length as a result of segmental demyelination and remyelination, and regeneration consecutive to fibre degeneration, which, as Eames and Lange (1967) also suggested, probably occurs in the aged owing to atheromatous occlusion of the vasa nervorum. Shortening of internodal length as a result of segmental demyelination and remyelination has been demonstrated in diabetics (Thomas and Lascelles, 1965, 1966) and in chronic uraemics (Asbury, Victor, and Adams, 1963; Forno and Alston1967), where conduction velocity is depressed even without definite evidence of periphera依 nerve disorders.

In normal subjects nerve conduction velocity is progressively reduced up to complete arrese during ischaemia (Magladery, McDougal, and $\vec{c}$ Stoll, 1950; Fullerton, 1963; Fox and Kenmore 1967; Seneviratne and Peiris, 1968a). Our results, however, provide evidence that the older the subjects, the longer the persistence of the evoked sensory responses and the less marked the slowing in conduction velocity. This longer resistance to ischaemia found in the older subjects resembles that observed in diabetes mellitus (Steiness, 1959, 1961 a and b; Castaigne, Cathala, Dry, and Mastropaolo, 1966; Arnott, Milbled, Delahousse, Fourlinnie, and Vandamme, 1968; Gregersen, 1968; Seneviratne and Peiris, 1968b; Christensen, Ørskov, and Terkildsen, 1970) and in chronic uraemia (Christensen and Ørskov, 1969; Christensen et al., 1970; Cathala, BaussartBoulence, Petrover, and Dammame, 1971); thus the question arises as to whether there is any relation between the segmental demyelination found in normal people above 60 years of age as well as in diabetic and uraemic patients and the slowing in nerve conduction with longer resistance to the effects of ischaemia.

On the enhanced resistance of diabetics to 
ischaemia, there is no general agreement as to whether the phenomenon is to be related to functional or to morphological changes of the peripheral nerves. Producing ischaemia in normal subjects with experimental induced hyperglycaemia, Steiness (1961a, b) failed to prolong the retention of vibration perception-time, at the same time demonstrating that normalization of the blood glucose level is unable to prevent the nerve fibres of diabetics from showing abnormally high resistance to ischaemia. On the other hand, from electron microscopic studies it has been demonstrated (Bischoff, 1968) that human diabetic subjects do exhibit structural abnormalities of the basement membrane of peripheral nerves. These changes, according to Seneviratne and Peiris $(1969,1970)$, would prevent surface concentration of potassium by increasing the permeability of the periaxonal diffusion barriers. In this way, potassium could not reach the level necessary to produce a depolarization block. However, peripheral nerves of chronic uraemic subjects (Christensen and Ørskov, 1969; Christensen et al., 1970; Cathala et al., 1971), of patients with pernicious anaemia (Christensen et al., 1970), and even of those with simple electrolyte deviations (Gregersen, 1970; Gregersen and Pilgaard, 1971) also exhibit increased resistance to ischaemia. Moreover, it has also been observed by Poole (1956b) that during 10 to 20 minutes of complete vascular occlusion of an upper limb, patients with 'acute or chronic polyneuritis' failed to exhibit ischaemic paraesthesiae and objective sensory impairment experienced by normal subjects. Thus, in the same way as there seems to be no simple relation between glucose and increased resistance to the effects of ischaemia, there is still considerable doubt as to the relative importance of the morphological changes in the basement membrane surrounding the Schwann cells, which should account for its increased permeability to potassium diffusion.

Our results do not allow any definite conclusion. We cannot, however, entirely rule out the hypothesis that a reduced saltatory distance determined by segmental demyelination of the nerve fibres may, on the one hand, cause reduction in conduction velocity and, on the other, permit conduction at lower values of membrane and action potential, in this way maintaining conduction of impulses for a longer period or complete circulatory arrest (Christensen and Ørskov, 1969; Christensen et al., 1970).

We would like to express our gratitude to the physicians, medical students, and nurses of the Clinic for Nervous and Mental Diseases, University of Bari, for having offered to undergo the experiments; to Professors G. A. Buscaino and E. Ferrari for their encouragement throughout this work; to Dr. G. Renzoni for his assistance in statistical analyses; and to Mrs. Valerie Cleverton-Basile and Mrs. Kirsten Lönegren-Caruso for correcting the English translation. Finally, we are particularly grateful to Professor F. Buchthal, Institute of Neurophysiology, University of Copenhagen, for his helpful advice and valuable comments.

\section{REFERENCES}

Arnott, G., Milbled, G., Delahousse, J., Fourlinnie, J.-C., and Vandamme, G. (1968). Résistance à l'ischémie du potentiel de nerf avec état diabétique latent: chez deux malades porteurs d'une neuropathie infra-clinique des membres inférieurs; chez un malade atteint de névrite multiple et successive. Lille Médical, 13, 294-298.

Asbury, A. K., Victor, M., and Adams, R. D. (1963). Uremic polyneuropathy. Archives of Neurology, 8, 413-428.

Behse, F., and Buchthal, F. (1971). Normal sensory conduction in the nerves of the leg in man. Journal of Neurology, Neurosurgery, and Psychiatry, 34, 404-414.

Bischoff, A. (1968). Diabetic neuropathy. German Medical Monthly, 13, 214-217.

Buchthal, F. (1972). Personal communication.

Buchthal, F., and Rosenfalck, A. (1966). Evoked action potentials and conduction velocity in human sensory nerves. Brain Research, 3, 1-122.

Castaigne, P., Cathala, H.-P., Dry, J., and Mastropaolo, C. (1966). Les réponses des nerfs et des muscles à des stimulations électriques au cours d'une épreuve de garrot ischémique chez l'homme normal et chez le diabétique. Revue Neurologique, 115, 61-66.

Cathala, H.-P., Baussart-Boulence, L., Petrover, M., and Dammame, J. (1971). Variations de la conduction et de l'excitabilité nerveuse au cours d'une épreuve d'ischémie chez les insuffisants rénaux. 4th International Congress of Electromyography. (Abstracts.) Brussels, 1971, pp. 27-28.

Christensen, N. J., and Ørskov, H. (1969). Vibratory perception during ischaemia in uraemic patients and in subjects with mild carbohydrate intolerance. Journal of Neurology, Neurosurgery, and Psychiatry, 32, 519-524.

Christensen, N. J., Ørskov, H., and Terkildsen, A. B. (1970). Abnormal vibratory perception during ischaemia in patients with diabetes mellitus, uraemia or pernicious anaemia. Acta Neurologica Scandinavica, 46, Suppl. 43, 203.

Eames, R. A., and Lange, L. S. (1967). Clinical and pathological study of ischaemic neuropathy. Journal of Neurology, Neurosurgery, and Psychiatry, 30, 215-226.

Forno, L., and Alston, W. (1967). Uremic polyneuropathy. Acta Neurologica Scandinavica, 43, 640-654.

Fox, J. L., and Kenmore, P. I. (1967). The effect of ischemia on nerve conduction. Experimental Neurology, 17, 403-419.

Fullerton, P. M. (1963). The effect of ischaemia on nerve conduction in the carpal tunnel syndrome. Journal of Neurology, Neurosurgery, and Psychiatry, 26, 385-397. 
Gregersen, G. (1968). A study of the peripheral nerves in diabetic subjects during ischaemia. Journal of Neurology, Neurosurgery, and Psychiatry, 31, 175-181.

Gregersen, G. (1970). Changes in nerve function during ischaemia in patients with diabetes mellitus or disturbances of calcium metabolism. Acta Neurologica Scandinavica, 46, Suppl. 43, 202.

Gregersen, G., and Pilgaard, S. (1971). The effect of ischaemia on vibration sense in hypo- or hypercalcaemia and in demyelinated nerves. Acta Neurologica Scandinavica, 47, 71-79.

Kugelberg, E. (1944). Accommodation in human nerves and its significance for the symptoms in circulatory disturbances and tetany. Acta Physiologica Scandinavica, 8, Suppl. 24.

Lascelles, R. G., and Thomas, P. K. (1966). Changes due to age in internodal length in the sural nerve in man. Journal of Neurology, Neurosurgery, and Psychiatry, 29, 40-44.

Lewis, T., Pickering, G. W., and Rothschild, P. (1931). Centripetal paralysis arising out of arrested blood flow to the limb, including notes on a form of tingling. Heart, 16, 1-32.

Magladery, J. W., McDougal, D. B., and Stoll, J. (1950). Electrophysiological studies of nerve and reflex activity in normal man. II. The effects of peripheral ischemia. Bulletin of the Johns Hopkins Hospital, 86, 291-312.

Nathan, P. W. (1958). Ischaemic and post-ischaemic numbness and paraesthesiae. Journal of Neurology, Neurosurgery, and Psychiatry, 21, 12-23.

Norris, E. H., Shock, N. W., and Wagman, I. H. (1953). Age changes in the maximum conduction velocity of motor fibers of human ulnar nerves. Journal of Applied Physiology, 5, 589-593.

O'Sullivan, D. J., and Swallow, M. (1968). The fibre size and content of the radial and sural nerves. Journal of Neurology, Neurosurgery, and Psychiatry, 31, 464-470.

Poole, E. W. (1956a). Ischaemic and post-ischaemic paraesthesiae. Normal responses in the upper limb with special reference to the effect of age. Journal of Neurology, Neurosurgery, and Psychiatry, 19, 148-154.

Poole, E. W. (1956b). Ischaemic and post-ischaemic par- aesthesiae in polyneuritis. Journal of Neurology, Neurosurgery, and Psychiatry, 19, 281-288.

Seneviratne, K. N., and Peiris, O. A. (1968a). The effect of ischaemia on the excitability of human sensory nerve. Journal of Neurology, Neurosurgery, and Psychiatry, 31, 338-347.

Seneviratne, K. N., and Peiris, O. A. (1968b). The effect of ischaemia on the excitability of sensory nerves in diabetes mellitus. Journal of Neurology, Neurosurgery, and Psychiatry, 31, 348-353.

Seneviratne, K. N., and Peiris, O. A. (1969). The effects of hypoxia on the excitability of the isolated peripheral nerves of alloxan-diabetic rats. Journal of Neurology, Neurosurgery, and Psychiatry, 32, 462-469.

Seneviratne, K. N., and Peiris, O. A. (1970). The role of diffusion barriers in determining the excitability of peripheral nerve. Journal of Neurology, Neurosurgery, and Psychiatry, 33, 310-318.

Steiness, I. (1959). Vibratory perception in diabetics during arrested blood flow to the limb. Acta Medica Scandinavica, 163, 195-205.

Steiness, I. (1961a). Vibratory perception in non-diabetic subjects during ischaemia, with special reference to the conditions in hyperglycaemia, after carbohydrate starvation and after cortisone administration. Acta Medica Scandinavica, 169, 17-26.

Steiness, I. (1961b). Influence of diabetic status on vibratory perception during ischaemia. Acta Medica Scandinavica, 170, 319-338.

Swallow, M. (1966). Fibre size and content of the anterior tibial nerve of the foot. Journal of Neurology, Neurosurgery, and Psychiatry, 29, 205-213.

Thomas, P. K., and Lascelles, R. G. (1965). Schwann-cel abnormalities in diabetic neuropathy. Lancet, 1, 1355-1357.

Thomas, P. K., and Lascelles, R. G. (1966). The pathology of diabetic neuropathy. Quarterly Journal of Medicine, 35, 489-509.

Weddell, G., and Sinclair, D. C. (1947). 'Pins and needles' observations on some of the sensations aroused in a limb by the application of pressure. Journal of Neurology, Neurosurgery, and Psychiatry, 10, 26-46. 